\title{
Impulsivity in the supermarket. Responses to calorie taxes and subsidies in healthy weight undergraduates
}

Citation for published version (APA):

Giesen, J. C. A. H., Havermans, R. C., Nederkoorn, C., \& Jansen, A. (2012). Impulsivity in the supermarket. Responses to calorie taxes and subsidies in healthy weight undergraduates. Appetite, 58(1), 6-10. https://doi.org/10.1016/j.appet.2011.09.026

Document status and date:

Published: 01/01/2012

DOI:

10.1016/j.appet.2011.09.026

Document Version:

Publisher's PDF, also known as Version of record

Document license:

Taverne

Please check the document version of this publication:

- A submitted manuscript is the version of the article upon submission and before peer-review. There can be important differences between the submitted version and the official published version of record.

People interested in the research are advised to contact the author for the final version of the publication, or visit the DOI to the publisher's website.

- The final author version and the galley proof are versions of the publication after peer review.

- The final published version features the final layout of the paper including the volume, issue and page numbers.

Link to publication

\footnotetext{
General rights rights.

- You may freely distribute the URL identifying the publication in the public portal. please follow below link for the End User Agreement:

www.umlib.nl/taverne-license

Take down policy

If you believe that this document breaches copyright please contact us at:

repository@maastrichtuniversity.nl

providing details and we will investigate your claim.
}

Copyright and moral rights for the publications made accessible in the public portal are retained by the authors and/or other copyright owners and it is a condition of accessing publications that users recognise and abide by the legal requirements associated with these

- Users may download and print one copy of any publication from the public portal for the purpose of private study or research.

- You may not further distribute the material or use it for any profit-making activity or commercial gain

If the publication is distributed under the terms of Article $25 \mathrm{fa}$ of the Dutch Copyright Act, indicated by the "Taverne" license above, 
Research report

\title{
Impulsivity in the supermarket. Responses to calorie taxes and subsidies in healthy weight undergraduates
}

\author{
Janneke C.A.H. Giesen*, Remco C. Havermans, Chantal Nederkoorn, Anita Jansen \\ Department of Clinical Psychological Science, Faculty of Psychology and Neuroscience, Maastricht University, P.0. Box 616, 6200 MD, Maastricht, The Netherlands
}

\section{A R T I C L E I N F O}

\section{Article history:}

Received 21 April 2011

Received in revised form 15 September 2011

Accepted 30 September 2011

Available online 12 October 2011

\section{Keywords:}

Obesity

Public policy

Behavioral economics

Impulsivity

Inhibitory control

\begin{abstract}
A B S T R A C T
The present study investigated the effect of taxing high-energy dense products and subsidizing lowenergy dense products on changes in calorie consumption. More specifically, we hypothesized that 'more impulsive' individuals were less influenced by such pricing strategies compared to 'less impulsive' individuals. Contrary to our hypothesis, results showed that 'more impulsive' individuals adjusted their calorie consumption with regard to price changes whereas 'less impulsive' participants were less influenced by price changes. Furthermore, taxing high-energy dense products was more successful in reducing calorie consumption than subsidizing low-energy dense products.
\end{abstract}

(c) 2011 Elsevier Ltd. All rights reserved.

\section{Introduction}

Excessive calorie consumption is one of the main causes for the current rise in obesity (Jéquier, 2002; Swinburn et al., 2009). Therefore promoting a healthier eating pattern is important. According to behavioral economic theory, unhealthy choices can be altered into healthier choices by increasing the price of the unhealthy choice or decreasing the price of the healthy choice. Studies using concurrent schedules tasks, where participants can work for highand low-calorie foods, show that the majority of participants switch from high-calorie foods to low-calorie foods when more effort is required to earn high-calorie foods (e.g., Giesen, Havermans, Douven, Tekelenburg, \& Jansen, 2010; Giesen, Havermans, \& Jansen, 2010; Giesen, Havermans, Nederkoorn, Strafaci, \& Jansen, 2009; Goldfield \& Epstein, 2002; Smith \& Epstein, 1991). Therefore it seems plausible that people will also switch from consuming or purchasing high-calorie foods to low-calorie foods when highcalorie foods become more expensive. The same shift in behavior may be observed when low-calorie foods become cheaper.

There are only a few studies examining the effects of manipulating food price on consumer behavior, and these studies all

\footnotetext{
is Acknowledgments: We would like to thank Michiel Vestjens and Charlie Bonnemayer for their technical assistance with the stop signal task and the internet supermarket task. Further we would like to thank Roy Haex for helping preparing the data for data-analyses and we would like to thank students Miriam Flosdorff, Annelijn Nijhuis, Sylvia Roozen, and Kathrin Schluper for their help in collecting the data.

* Corresponding author.

E-mail address: janneke.giesen@maastrichtuniversity.nl (J.C.A.H. Giesen).
}

suggest that such pricing strategies have an immediate effect. French et al. (2001) showed that sales of low-fat snacks in vending machines could increase with 9\%, 39\% and even 93\% when the prices were reduced with $10 \%, 25 \%$ and $50 \%$ respectively. However, Epstein, Dearing, Roba, and Finkelstein (2010) found that subsidizing more healthful high nutrient dense foods (e.g., nonfat yogurt and broccoli) resulted in a paradoxical increase in energy intake. Why subsidizing low-energy dense products can lead to increased energy consumption is not clear. Epstein et al. (2010) suggest that when low-energy dense products get subsidized, people might save money that can be spent on high-energy dense products.

The study by Epstein et al. (2010) also showed that a tax on less healthy low nutrient dense foods (e.g., hot dogs and potato chips) reduced energy intake (see also, Epstein, Dearing, Paluch, Roemmich, \& Cho, 2007; Epstein et al., 2006; Nederkoorn, Havermans, Giesen, \& Jansen, 2011). In our lab, we recently found a similar result; that is, when increasing the price (i.e., taxing) of high-calorie products on a lunch menu the number of calories chosen for lunch decreased (Giesen, Payne, Havermans, \& Jansen, 2011). Hence, a tax on high-energy dense foods appears beneficial in promoting healthier eating (i.e., consuming less calories). Nonetheless, there are good reasons to suspect that not everyone will be equally susceptible to a high-calorie food tax. Clearly, some people find it more difficult than others to resist the temptation to indulge oneself with a high-calorie treat. Some researchers have argued that it is impulsivity that underlies this individual difference. Indeed, both overeating and overweight/obesity are associated with impulsivity (Guerrieri, Nederkoorn, \& Jansen, 2007; Jansen et al., 2009; Nederkoorn, Braet, Van Eijs, Tanghe, \& Jansen, 2006). Impulsivity 
has also been found to influence the purchase of calories from highenergy dense food products in an internet supermarket, especially hungry impulsive participants bought more calories (Nederkoorn, Guerrieri, Havermans, Roefs, \& Jansen, 2009). Impulsivity is a broad concept referring to responding with insufficient forethought, planning or control (Solanto et al., 2001). One aspect of impulsivity is impaired inhibitory control (Solanto et al., 2001). Conceivably, someone who has difficulty overriding an automatic response to palatable high-calorie foods may not be very responsive to a price change. In other words, impulsive people presumably tend to buy snack food without much consideration of its price.

In the current study we investigated if taxing high-energy dense foods and subsidizing low-energy dense foods influences the number of calories bought for groceries in an internet supermarket. Moreover, we tested whether this tax and subsidy differently influence 'more impulsive' individuals compared to 'less impulsive' controls. In line with Epstein's findings (2010) we hypothesized that a tax on high-energy dense foods would be more efficient in decreasing the number of calories bought by participants, compared to a subsidy on low-energy dense foods. Further we hypothesized that this effect would be more prominent in the 'less impulsive' individuals.

\section{Method}

\section{Participants}

Participants were 82 undergraduate students from Maastricht University in the Netherlands of which 61 were female. Students were invited to take part in an experiment concerning shopping behavior in return for course credits. Two participants had more than a $95 \%$ error rate on the stop signal task (Logan, Schachar, \& Tannock, 1997) and 10 participants did not follow the instructions for the internet supermarket task. Data from these 12 ( 8 female) participants were excluded from analyses, leaving us with 70 participants. Participants were randomly assigned to either the tax or subsidy condition. Based on a median split on stop signal reaction time $($ SSRT) $($ median $=319.25)$ the two conditions were each divided in a high SSRT (more impulsive) and low SSRT (less impulsive) group. A summary of group characteristics is given in Table 1. This study was approved by the ethical committee of the Faculty of Psychology and Neuroscience at Maastricht University.

\section{Procedure and materials}

Participants were tested in groups of 5-7 individuals, between $11 \mathrm{AM}$ and 4 PM. Participants were instructed to refrain from eating and drinking (except water) $2 \mathrm{~h}$ prior to participation. Upon arriving in the laboratory each participant was seated in a private cubicle and was given a written description about the procedure and signed a consent form.

Participants were asked to indicate their momentary hunger on a $100 \mathrm{~mm}$ Visual Analogue Scale (VAS; "not at all hungry" to 100 "very hungry") to be able to check whether the groups differed on initial hunger. Then the participants started the stop signal task (Logan et al., 1997). The stop signal task is a choice reaction time task that measures response inhibition and that has been related to impulsivity (Logan et al., 1997). In this task a participant must respond as fast as possible to a go signal (in this case, the letter ' $e$ ' or ' $u$ ') by pressing the corresponding letter on the keyboard. However, when a stop signal appears (a red circle around the letter), the response must be inhibited ( $25 \%$ of the trials). The delay of the stop-signal is initially set at $250 \mathrm{~ms}$ after the presentation of the go signal, and then dependent on the response from the participant adjusted dynamically. The stop signal reaction time (SSRT) is calculated by subtracting the stop delay from the reaction time (RT). A higher SSRT is regarded as lower inhibitory control (more impulsive). Participants first performed a short practice block of 10 trials to practice responding to the different go signals. Next, there were two blocks of 80 test trials. Between the two blocks, participants were allowed to take a short break (approximately $1 \mathrm{~min}$ ), while staying in their own cubicle.

After the stop signal task, participants were instructed to buy groceries in an internet supermarket task (Nederkoorn et al., 2009). The instruction for the students was as follows (translated from Dutch):

Imagine it is a regular Tuesday and you have no food at home. It is time to go grocery shopping, but only for this whole day. To this end, you now receive $€ 10$ to buy groceries for yourself for today. Note that you already have oil, butter and spices in stock at home. Have fun shopping!

When finished doing groceries, they were asked to buy groceries for a second time, with almost similar instructions:

Imagine it is Tuesday, a week later, and again you have no food at home. So you need to go grocery shopping again. The supermarket where you went last week is closed, therefore you need to go to another supermarket. You receive $€ 10$ to buy groceries for yourself for this whole day. Oil, butter and spices are already in stock at home. Have fun shopping!

The first time participants performed the internet supermarket task, the shop was the same for every participant with prices equivalent to product prices in regular supermarkets in the Netherlands. The second time, participants were randomly assigned to a tax or subsidy condition. In the tax condition, all products (drinks and juices excluded) with a energy density of $300 \mathrm{kcal} / 100 \mathrm{~g}$ and above (high-energy dense products) were raised in price with $50 \%$. In the subsidy condition all products (drinks and juices excluded) with a energy density of $150 \mathrm{kcal} / 100 \mathrm{~g}$ and below (low-energy dense products) were reduced in price with $50 \%$. The products with an energy density in between 150 and $300 \mathrm{kcal} / 100 \mathrm{~g}$ (moderate-energy dense products), plus the soft drinks, beverages and juices stayed at the same price for both conditions. The original internet supermarket (see Nederkoorn et al., 2009) was extended from 640 products to 708 food products. In total 233 products classified as high-energy dense products, 217 as moderate-energy dense products, and 258 as low-energy dense products.

Table 1

Means with standard errors of group characteristics.

\begin{tabular}{|c|c|c|c|c|c|c|c|c|}
\hline \multirow[t]{3}{*}{ Variable } & \multicolumn{4}{|l|}{ Tax } & \multicolumn{4}{|c|}{ Subsidy } \\
\hline & \multicolumn{2}{|c|}{ Low SSRT $(N=15)$} & \multicolumn{2}{|c|}{ High SSRT $(N=16)$} & \multicolumn{2}{|c|}{ Low SSRT $(N=20)$} & \multicolumn{2}{|c|}{ High SSRT $(N=19)$} \\
\hline & $M$ & $S E$ & $M$ & $S E$ & $M$ & $S E$ & $M$ & $S E$ \\
\hline Age & 21.6 & 0.46 & 21.5 & 0.57 & 21.3 & 0.37 & 22.0 & 0.63 \\
\hline Hunger (100 mm) & 44.1 & 7.46 & 48.3 & 6.41 & 57.9 & 5.24 & 50.6 & 5.55 \\
\hline BMI $\left(\mathrm{kg} / \mathrm{m}^{2}\right)$ & 23.4 & 0.70 & 22.9 & 0.79 & 23.0 & 1.19 & 23.3 & 0.64 \\
\hline SSRT & 264.3 & 6.76 & 377.2 & 9.17 & 269.9 & 7.38 & 361.9 & 8.00 \\
\hline
\end{tabular}


When finished with the internet supermarket task, participants were guided to a separate room where height and weight were measured to calculate Body Mass Index (BMI; $\mathrm{kg} / \mathrm{m}^{2}$ ).

\section{Design and analyses}

The dependent variable was the difference in the number of calories bought between the first supermarket with normal price and the second supermarket with tax or subsidy (supermarket 2 -supermarket 1 ). A negative score thus represents a decrease in calories bought, whereas a positive score indicates an increase in purchased calories. We calculated four difference scores: (1) for the total number of calories; (2) for the number of calories from the high-energy dense products; (3) for the number of calories from the moderate-energy dense products; and (4) for the number of calories from the low-energy dense products. Data were analyzed in four 2 (condition: tax vs subsidy) $\times 2$ (impulsivity: low SSRT vs high SSRT) ANOVAs (analysis of variance). Partial eta squared $\left(\eta_{\mathrm{p}}^{2}\right)$ is reported as a measure of effect size.

\section{Results}

\section{Participants}

To test if groups differed in age, initial hunger, BMI and SSRT, separate ANOVA's on these group characteristics were conducted. The analysis concerning age revealed no main effects for condition $F(1,66)=.02, p=.886, \eta_{\mathrm{p}}^{2}<.001$, or impulsivity $F(1,66)=.39$, $p=.535, \eta_{\mathrm{p}}^{2}=.006$. Further, there was no significant interaction effect for condition $\mathrm{x}$ impulsivity, $F(1,66)=.67, p=.418, \eta_{\mathrm{p}}^{2}=.010$, indicating that the groups did not differ in age.

With regard to hunger, no main effects were found for either condition $F(1,66)=1.74, p=.192, \eta_{\mathrm{p}}^{2}=.026$ or impulsivity $F(1$, $66)=.06, p=.800, \eta_{\mathrm{p}}^{2}=.001$. No significant condition $\times$ impulsivity interaction effect was found, $F(1,66)=.86, p=.357, \eta_{\mathrm{p}}^{2}=.013$, indicating that the groups did not differ on initial hunger.

For BMI, similar results were found, that is, no main effects for condition $F(1,64)^{1}<.01, p=.966, \eta_{\mathrm{p}}^{2}<.001$ and for impulsivity, $F(1$, $64)=.02, p=.880, \eta_{\mathrm{p}}^{2}<.001$, and the absence of an interaction effect for condition $\mathrm{x}$ impulsivity, $F(1,64)=.19, p=.664, \eta_{\mathrm{p}}^{2}=.003$ was found suggesting that the groups did not differ in BMI.

As expected, for SSRT there was a significant main effect for impulsivity, $F(1,66)=165.20, p<.001, \eta_{\mathrm{p}}^{2}=.715$, indicating that the median split on SSRT resulted in two distinctive groups. Neither a main effect for condition was found, $F(1,66)=.37, p=.546$, $\eta_{\mathrm{p}}^{2}=.006$, nor a significant interaction effect for condition $\times$ impulsivity, $F(1,66)=1.71, p=.195, \eta_{\mathrm{p}}^{2}=.025$.

\section{Total calories}

To check for pre-test differences between groups a 2 (condition: tax vs subsidy) $\times 2$ (impulsivity: low SSRT vs high SSRT) ANOVA on the number of calories bought in the first supermarket was performed. This analysis revealed no main effects for condition, $F(1$, $66)=.19, \quad p=.663, \eta_{\mathrm{p}}^{2}=.003$, or impulsivity, $F(1,66)=.90$, $p=.346, \eta_{\mathrm{p}}^{2}=.013$. Further, the interaction effect of condition $\times$ impulsivity was not significant, $F(1,66)=1.05, p=.310$, $\eta_{\mathrm{p}}^{2}=.016$, suggesting that the groups did not differ on the number of calories bought in the first supermarket.

The ANOVA on difference scores for total calories revealed a significant main effect for condition $F(1,66)=7.73, p=.007$, $\eta_{\mathrm{p}}^{2}=.105$. This main effect was qualified by a marginally

\footnotetext{
${ }^{1}$ Note that the degrees of freedom are different from the other analysis, because of missing variables in two cases.
}

significant interaction effect of condition $\times$ impulsivity, $F(1$, $66)=3.24, p=.076, \eta_{\mathrm{p}}^{2}=.047$. This interaction effect suggests that in the tax condition, only high SSRT participants decrease the number of calories they buy, whereas in the subsidy condition, low SSRT and even more so high SSRT participants increase the number of calories, as can be seen in Fig. 1. No significant main effect was found for impulsivity, $F(1,66)<.001$.

Post-hoc tests testing whether the high and low Impulsive groups differ from each other within condition revealed no significant effects (within tax: $t(29)=1.32, p=.197$; within subsidy: $t(37)=1.27, p=.211)$. We further tested whether per group the change in calories between the first and second supermarket was significant. These analyses revealed that the high SSRT participants significantly decreased the number of calories purchased in the tax condition, $t(15)=2.41, p=.03$, and increased the number of calories bought in the subsidy condition, $t(18)=2.67, p=.016$. For the low SSRT participants no significant changes in total calorie purchase were found for either the tax or subsidy condition, $t$ 's $<1.52$, p's $>.144$.

\section{Calories from the high-energy dense products}

To check for pre-test differences between groups a 2 (condition: tax vs subsidy) $\times 2$ (impulsivity: low SSRT vs high SSRT) ANOVA on the number of calories bought from high-energy dense products in the first supermarket was performed. This analysis revealed no main effects for condition, $F(1,66)=1.34, p=.251, \eta_{\mathrm{p}}^{2}=.020$, or impulsivity, $F(1,66)=.66, p=.418, \eta_{\mathrm{p}}^{2}=.010$. Also the interaction effect of condition $\times$ impulsivity was not significant, $F(1$, $66)=1.32, p=.254, \eta_{\mathrm{p}}^{2}=.020$. These results suggest that the groups did not differ in the number of calories bought from highenergy dense products in the first supermarket.

To examine whether tax or subsidy had a specific effect on the calories bought from high-energy dense products an ANOVA was performed on the difference scores for calories of high-energy dense products. This analysis revealed no significant main effects for either condition, $F(1,66)=1.14, p=.289, \eta_{\mathrm{p}}^{2}=.017$, or impulsivity, $F(1,66)=.26, p=.612, \eta_{\mathrm{p}}^{2}=.004$. However, a significant interaction effect of condition $\times$ impulsivity was found, $F(1$, $66)=8.15, p=.006, \eta_{\mathrm{p}}^{2}=.110$, showing that in the tax condition the high SSRT participants decreased the number of calories bought from high-energy dense products, whereas the low SSRT participants slightly increased the number of calories. In the subsidy condition this pattern was reversed, see Fig. 2a.

Post-hoc tests revealed that high and low SSRT participants significantly differed from each other in the tax condition, $t(29)=2.07, p=.047$ and in the subsidy condition, $t(37)=2.19$,

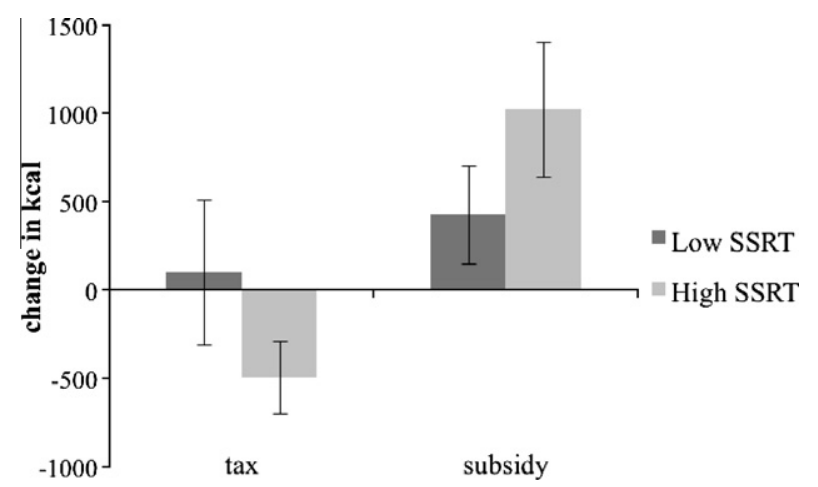

Fig. 1. Change in calories between first time shopping en second time shopping, for high and low SSRT individuals in the tax and subsidy condition. The error bars represent one standard error. A negative score constitutes a decrease in calories; a positive score represents an increase in calories. 
$p=.035$. The high SSRT participants significantly decreased the number of calories bought from the high-energy dense products in the tax condition, $t(15)=2.30, p=.036$, and in the subsidy condition the high SSRT participants significantly increased the number of calories purchased, $t(18)=2.19, p=.042$. Changes in bought calories for the low SSRT participants were not significant, t's $<.93, p$ 's $>.369$.

\section{Calories from the moderate-energy dense products}

To check for pre-test differences between groups a 2 (condition: tax vs subsidy) $\times 2$ (impulsivity: low SSRT vs high SSRT) ANOVA on the number of calories bought from moderate-energy dense products in the first supermarket was performed. This analysis revealed no main effects for condition, $F(1,66)=.07, p=.792, \eta_{\mathrm{p}}^{2}=.001$, or impulsivity, $F(1,66)=.09, p=.764, \eta_{\mathrm{p}}^{2}=.001$. Also the interaction effect of condition $\mathrm{x}$ impulsivity was not significant, $F(1$, $66)=.33, p=.568, \eta_{\mathrm{p}}^{2}=.005$. These results suggest that the groups
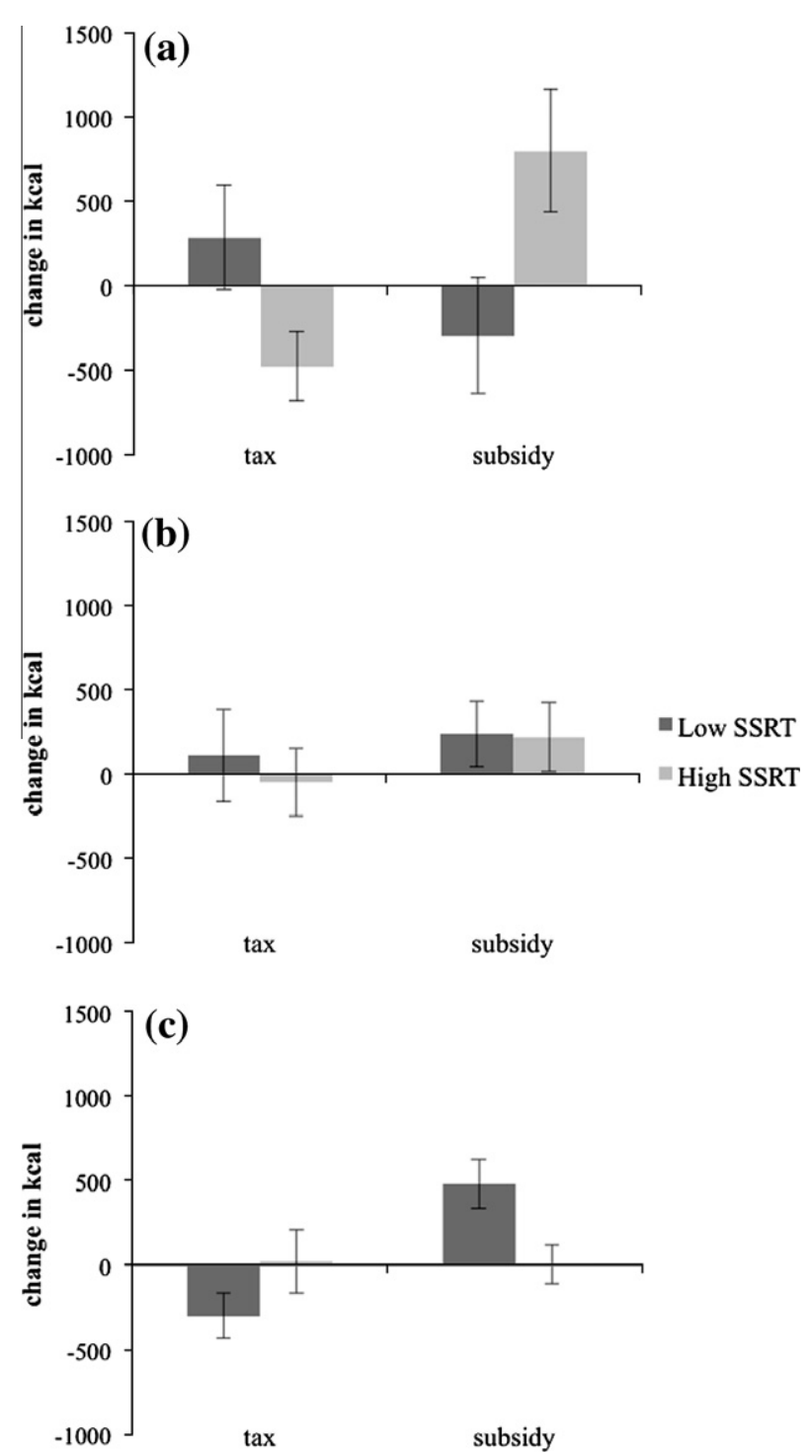

Fig. 2. Change in calories from (a) high-energy dense products, (b) moderateenergy dense products and (c) low energy dense products between first time shopping en second time shopping, for high and low SSRT individuals in the tax and subsidy condition. The error bars represent one standard error. A negative score constitutes a decrease in calories; a positive score represents an increase in calories. did not differ on the number of calories bought from moderateenergy dense products in the first supermarket.

Tax, subsidy or impulsivity seemed to have little or no effect on the consumption of moderate-energy dense products, see Fig. $2 \mathrm{~b}$. No main effects for condition, $F(1,66)=.80, p=.375, \eta_{\mathrm{p}}^{2}=.012$, or for impulsivity were found, $F(1,66)=.18, p=.685, \eta_{\mathrm{p}}^{2}=.003$. There was no condition $\mathrm{x}$ impulsivity interaction effect, $F(1,66)=.10$, $p=.753, \eta_{\mathrm{p}}^{2}=.002$. As is displayed in Fig. $2 \mathrm{~b}$, low and high SSRT participants show only minimal changes in calories from moderateenergy dense products for both tax and subsidy.

\section{Calories from the low-energy dense products}

To check for pre-test differences between groups a 2 (condition: tax vs subsidy) $\times 2$ (impulsivity: low SSRT vs high SSRT) ANOVA on the number of calories bought from low-energy dense products in the first supermarket was performed. This analysis revealed no main effects for condition, $F(1,66)=1.93, p=.170, \eta_{\mathrm{p}}^{2}=.028$, or for impulsivity, $F(1,66)=.51, p=.480, \eta_{\mathrm{p}}^{2}=.008$. Further, the interaction effect of condition $\times$ impulsivity proved not significant, $F(1$, $66)=1.32, p=.255, \eta_{\mathrm{p}}^{2}=.020$, suggesting that the groups did not differ on the number of calories bought from low-energy dense products in the first supermarket.

The ANOVA on the difference scores for the calories from the low-energy dense products showed a significant main effect of condition, $F(1,66)=6.67, p=.012, \eta_{\mathrm{p}}^{2}=.092$, which was qualified by a significant interaction effect of condition $\times$ impulsivity, $F(1$, $66)=7.41, p=.008, \eta_{\mathrm{p}}^{2}=.101$. No significant main effect was found for impulsivity, $F(1,66)=.27, p=.604, \eta_{\mathrm{p}}^{2}=.004$. As can be seen in Fig. 2c, the low SSRT participants in the tax condition decreased their purchase of calories from the low-energy dense products whereas in the subsidy condition they increased their purchase of calories from the low-energy dense products. The high SSRT participants showed no change in buying calories for low-energy dense products in both conditions.

Post-hoc tests revealed no difference between high- and low SSRT participants in the tax condition, $t(29)=1.38, p=.177$, but they did differ in the subsidy condition, $t(37)=2.58, p=.014$. As suggested above, only the low SSRT participants significantly changed the number of calories purchased in the tax condition, $t(14)=2.25, p=.041$. And in the subsidy condition, they bought more calories from the subsidized low-energy dense products and less calories from low-energy dense products in the tax condition, $t(19)=3.35, p=.003$. For the high SSRT participants changes were not significant, $t$ 's $<.13, p$ 's $>.897$.

The absolute number of calories bought per group, for all products, high-energy dense products, moderate-dense products, and low-energy dense products in both supermarket 1 and 2 are displayed in Table 2 .

\section{Discussion}

The present study investigated the effect of a calorie tax on high-energy dense products and a subsidy for low-energy dense products on the number of calories purchased. Furthermore, we investigated if 'more impulsive' individuals are less influenced by price changes compared to 'less impulsive' individuals.

Contrary to our hypothesis, we found that especially the more impulsive individuals with lower response inhibition responded to the price changes. In the tax condition, the 'more impulsive' individuals decreased the number of calories they bought. These calories were mainly purchased from high-energy dense products. In the subsidy condition, the 'more impulsive' individuals increased the number of calories they bought, also mainly from high-energy dense products. The 'more impulsive' participants 
Table 2

Means with standard errors of kcal bought per group.

\begin{tabular}{|c|c|c|c|c|c|c|c|c|}
\hline \multirow[t]{3}{*}{ Variable } & \multicolumn{4}{|l|}{ Tax } & \multicolumn{4}{|c|}{ Subsidy } \\
\hline & \multicolumn{2}{|c|}{ Low SSRT N = 15} & \multicolumn{2}{|c|}{ High SSRT N = 16} & \multicolumn{2}{|c|}{ Low SSRT N = 20} & \multicolumn{2}{|c|}{ High SSRT N = 19} \\
\hline & $M$ & $S E$ & M & $S E$ & $M$ & $S E$ & $M$ & $S E$ \\
\hline \multicolumn{9}{|l|}{ First supermarket } \\
\hline Total calories & 3797 & 362 & 4358 & 387 & 4213 & 235 & 4192 & 152.0 \\
\hline Calories high-energy dense & 1379 & 267 & 1947 & 360 & 2046 & 292 & 1949 & 222.1 \\
\hline Calories moderate-energy dense & 1451 & 158 & 1497 & 196 & 1503 & 161 & 1357 & 147.1 \\
\hline Calories low-energy dense & 967 & 118 & 915 & 99 & 664 & 103 & 886 & 142.4 \\
\hline \multicolumn{9}{|l|}{ Second supermarket } \\
\hline Total calories & 3896 & 304 & 3860 & 277 & 4637 & 257 & 5214 & 352.5 \\
\hline Calories high-energy dense & 1666 & 224 & 1471 & 327 & 1752 & 268 & 2750 & 260.6 \\
\hline Calories moderate-energy dense & 1562 & 219 & 1449 & 153 & 1740 & 212 & 1573 & 177.6 \\
\hline Calories low-energy dense & 668 & 73 & 940 & 170 & 1146 & 124 & 890 & 108.0 \\
\hline
\end{tabular}

did not change their purchase of low-energy dense products in the subsidy condition. However, since low-energy dense products were cheaper in the subsidy condition, money was saved on these products that in turn could be spent on high-energy dense products. The 'less impulsive' participants increased the number of bought calories from low-energy dense products in the subsidy condition. It can thus be concluded that for 'less impulsive' people a subsidy on low-energy dense products is effective in generating a healthier diet with relatively more low-energy dense products. For 'more impulsive' people a subsidy appears however counterproductive leading to the purchase of more high-energy dense products. For 'more impulsive' people a tax on high-energy dense products results in a healthier diet: the tax leads them to buy less high-energy dense products. 'Less impulsive' people are unaffected by this intervention.

Possibly, 'less impulsive' individuals adhere to a meticulous approach to buying their groceries. Therefore, when a tax or subsidy is introduced they do not readily change their shopping list, because they carefully thought about each product on that list. Consequently they stick to their list and only add some cheaper low-energy dense products. For the 'more impulsive' individuals, the first time grocery shopping may not really be that wellplanned, but the second time, when the prices changed in the tax condition, they quickly noticed that they would run out of budget much faster, and then reconsidered their groceries. In the subsidy condition, they actually saved money on the low-energy dense products, so that they could indulge more on the high-energy dense products. This is of course post-hoc reasoning and more research is required to find out why 'more impulsive' persons are more sensitive to product price manipulations.

In the current research we only studied a relatively small sample of healthy undergraduate students. Future research should examine if the results also extend to a larger more representative sample of impulsive and non-impulsive individuals. Note that we do not know if performing the supermarket task twice in a row may have an impact on the participants' shopping behavior. The magnitude of this potential order effect is unclear, but we can assume that the effect is equal between the groups. Furthermore, we did not measure differences in social economic status. This may however be a useful factor to include in future research. Another aspect related to impulsivity is choosing a smaller immediate reward over a larger delayed reward, also known as delay discounting. Research has shown that the interaction between delay discounting and food reinforcement predicts food intake (see, Epstein, Salvy, Carr, Dearing, \& Bickel, 2010). It would be interesting to see if individual differences in delay discounting are associated with the purchase of food in a similar manner as variation in behavioral inhibition appears to moderate the effect of food taxes and subsidies on food purchasing as shown in the current study.
The present study corroborates the notion that subsidizing lowenergy dense food is beneficial for one group of people (less impulsive) whereas it appears counterproductive in another group of people (more impulsive). However, taxing high-energy dense products is not disadvantageous for any group.

\section{References}

Epstein, L. H., Dearing, K. K., Paluch, R. A., Roemmich, J. N., \& Cho, D. (2007). Price and maternal obesity influence purchasing of low- and high-energy-dense foods. The American Journal of Clinical Nutrition, 86, 914-922.

Epstein, L. H., Dearing, K. K., Roba, L. G., \& Finkelstein, E. (2010). The influence of taxes and subsidies on energy purchased in an experimental purchasing study. Psychological Science, 21, 406-414.

Epstein, L. H., Handley, E. A., Dearing, K. K., Cho, D. D., Roemmich, J. N., Paluch, R. A., et al. (2006). Purchases of food in youth. Influence of price and income. Psychological Science, 17, 82-89.

Epstein, L. H., Salvy, S. J., Carr, K. A., Dearing, K. K., \& Bickel, W. K. (2010). Food reinforcement, delay discounting and obesity. Physiology and Behavior, 100, 438-445.

French, S. A., Jeffery, R. W., Story, M., Breitlow, K. K., Baxter, J. S., Hannan, P., et al. (2001). Pricing and promotion effects on low-fat vending snack purchases. The CHIPS study. American Journal of Public Health, 91, 112-117.

Giesen, J. C. A. H., Havermans, R. C., Douven, A., Tekelenburg, M., \& Jansen, A. (2010) Will work for snack food. The association of BMI and snack reinforcement. Obesity, 18, 966-970.

Giesen, J. C. A. H., Havermans, R. C., \& Jansen, A. (2010). Substituting snacks with strawberries and sudokus. Does restraint matter? Health Psychology, 29 222-226.

Giesen, J. C. A. H., Havermans, R. C., Nederkoorn, C., Strafaci, S., \& Jansen, A. (2009) Working harder to obtain more snack foods when wanting to eat less. Behaviour Research and Therapy, 47, 13-17.

Giesen, J. C. A. H., Payne, C. R., Havermans, R. C., \& Jansen, A. (2011). Exploring how calorie information and taxes on high-calorie foods influence lunch decisions. American Journal of Clinical Nutrition, 93, 689-694.

Goldfield, G. S., \& Epstein, L. H. (2002). Can fruits and vegetables and activities substitute for snack foods? Health Psychology, 21, 299-303.

Guerrieri, R., Nederkoorn, C., \& Jansen, A. (2007). How impulsiveness and variety influence food intake in a sample of healthy women. Appetite, 48, 119-122.

Jansen, A., Nederkoorn, C., van Baak, L., Keirse, C., Guerrieri, R., \& Havermans, R. (2009). High-restrained eaters only overeat when they are also impulsive. Behaviour Research and Therapy, 47, 105-110.

Jéquier, E. (2002). Pathways to obesity. International Journal of Obesity, 26(Suppl.), 12-17.

Logan, G. D., Schachar, R., \& Tannock, R. (1997). Impulsivity and inhibitory control. Psychological Science, 8, 60-64.

Nederkoorn, C., Braet, C., Van Eijs, Y., Tanghe, A., \& Jansen, A. (2006). Why obese children cannot resist food. The role of impulsivity. Eating Behaviors, 7, 315-322.

Nederkoorn, C., Guerrieri, R., Havermans, R. C., Roefs, A., \& Jansen, A. (2009). The interactive effect of hunger and impulsivity on food intake and purchase in a virtual supermarket. International Journal of Obesity, 33, 905-912.

Nederkoorn, C., Havermans, R. C., Giesen, J. C. A. H., \& Jansen, A. (2011). High tax on high energy dense foods and its effects on the purchase of calories in a supermarket. An experiment. Appetite, 56, 760-765.

Smith, J. A., \& Epstein, L. H. (1991). Behavioral economic analysis of food choice in obese children. Appetite, 17(2), 91-95.

Solanto, M. V., Abikoff, H., Sonuga-Barke, E., Schachar, R., Logan, G. D., Wigal, T., et al (2001). The ecological validity of delay aversion and response inhibition as measures of impulsivity in $\mathrm{AD} / \mathrm{HD}$. A supplement to the NIMH multimodal treatment study of AD/HD. Journal of Abnormal Child Psychology, 29, 215-228.

Swinburn, B. A., Sacks, G., Lo, S. K., Westerterp, K. R., Rush, E. C., Rosenbaum, M., et al. (2009). Estimating the changes in energy flux that characterize the rise in obesity prevalence. American Journal of Clinical Nutrition, 89, 1723-1728. 